sala preta ppgac

\title{
Da sala preta ao jardim
}

From black box to the orchard

\section{Marcelo Lazzaratto}

Marcelo Lazzaratto

Diretor teatral, diretor artístico da Cia. Elevador de Teatro Panorâmico e professor do

Departamento de Artes Cênicas da Unicamp

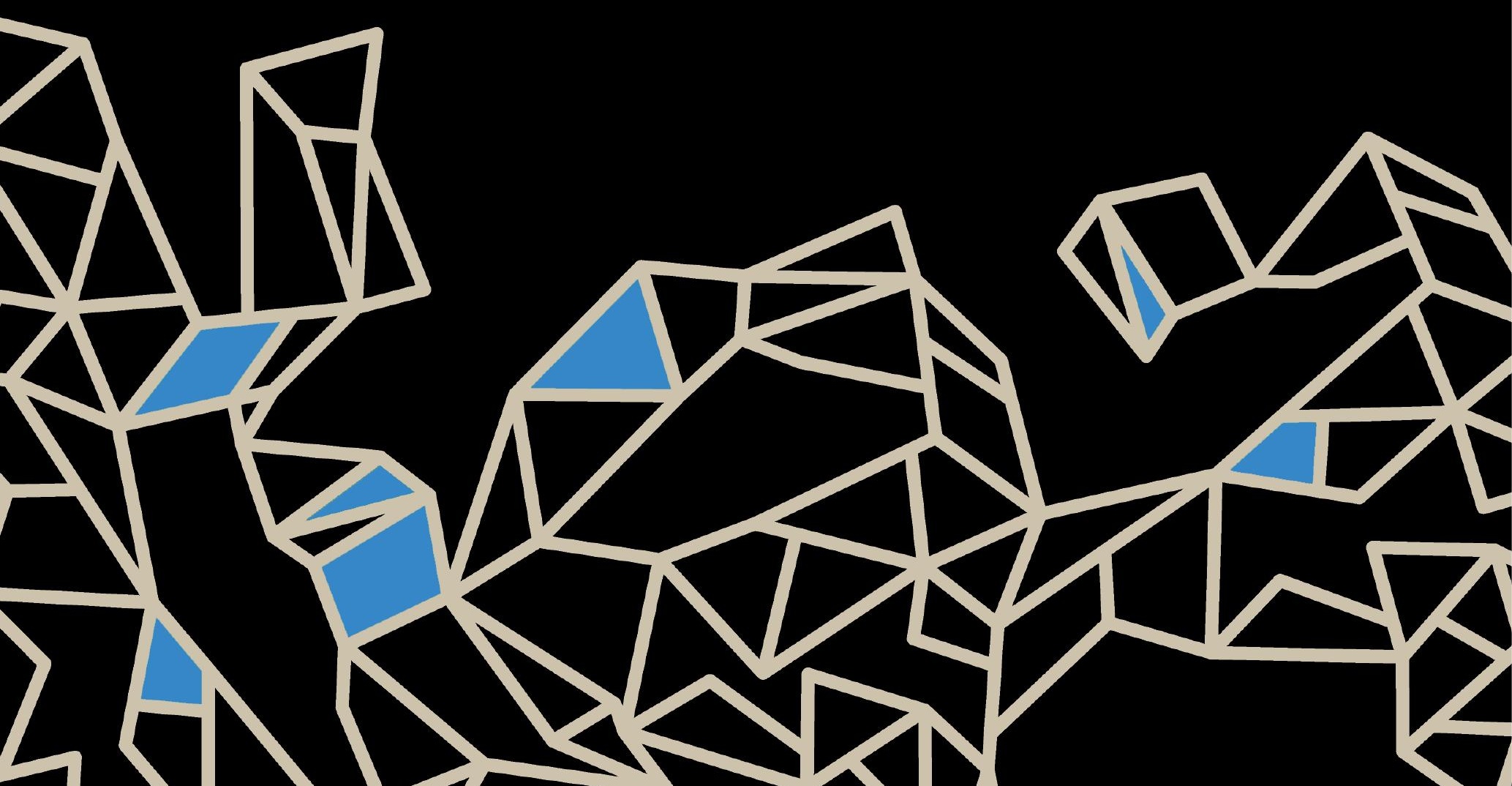




\section{Resumo}

Este artigo expõe a aproximação de um diretor teatral com a iluminação cênica, revelando o amálgama existente entre essas duas instâncias do trabalho criativo, através da análise dos procedimentos estéticos processados em três espetáculos dirigidos e iluminados pelo autor.

Palavras-chave: Iluminação cênica, Direção teatral, Procedimentos estéticos.

\section{Abstract}

This paper presents the approach of a theater director to theatrical lighting, revealing the existing mix between these two instances of creative work, by analyzing the aesthetic procedures used in three productions directed and enlightened by the author.

Keywords: Stage lighting, Theatrical direction, Aesthetic procedures.

No final da década de 1980, eu era aluno do Departamento de Artes Cênicas da Escola de Comunicação e Artes da Universidade de São Paulo. Lembro que, em um semestre, ocorreram 36 montagens extracurriculares. A sala preta era o local em que elas aconteciam. $O$ curso naquele tempo era matutino. Durante as tardes criávamos nossos projetos, ensaiávamos, nos preparávamos para trazer à cena aquilo que acreditávamos ser nossa genuína expressão. Ingênuos ou loucos, prepotentes ou profetas, não importa, o que interessa é dizer que nos formávamos simultaneamente nas aulas regulares e nas tardes ensolaradas na preta sala.

A sala preta era o tubo de ensaio onde tudo acontecia. O local dos experimentos. O local dos sonhos e devaneios. O local de ousadia e inquietação. Ali tive muitas ideias. Ideias boas, ideias ruins. Ali pude materializar meu primeiro texto, Tantas vezes pareço. Imagine eu, um dramaturgo, com as atrizes companheiras de turma, em que pude ser, além de autor, diretor, cenógrafo, sonoplasta e iluminador. Não devíamos nada a ninguém, porque não sabíamos nada. Éramos livres para entender e descobrir. 
Quando fui convidado por Guilherme Bonfanti e Silvia Fernandes para escrever um artigo para a Sala Preta sobre diretores que iluminam, não pude deixar de voltar no tempo e, rapidamente, relembrar os primeiros passos que de fato orientaram minhas escolhas futuras e que ainda estão presentes em mim, como pessoa de teatro.

Na sala preta tínhamos aulas de iluminação com o saudoso Amilton Saraiva, que nos mostrava as características de cada refletor, dos filtros, do uso e dos recursos da mesa analógica de 24 canais, além das aulas básicas em eletricidade. E, o mais importante, nos deixava livres para experimentar, em nossas montagens extracurriculares, as "luzes" que quiséssemos.

Assim, tive espaço e oportunidade de subir em escadas, colocar, afinar e retirar refletores, puxar extensões, rackear, construir ribaltas e refletores com latas, experimentar luz indireta usando restos de espelhos da cenografia e tudo o mais que poderia inventar com os poucos recursos de que dispúnhamos. Foi ali que ouvi de Marcio Aurélio, então professor e depois meu diretor por dez anos na Cia. Razões Inversas, o termo "bateria de luz", quando montamos, como peça de formatura do quarto ano, Mauser, de Heiner Müller. Antes de ver a coisa pronta me perguntava: o que seria uma bateria de luz, como seria feita? ${ }^{1}$ Nessa mesma montagem comecei a entender quanto a luz poderia ser uma grande aliada da dramaturgia, e também capaz de escrever ela própria uma dramaturgia cênica. Depois disso, a luz para mim não somente iluminava como também criava. A luz virou linguagem. $E$ talvez tenha sido nesse momento que o diretor começou a se formar em mim. A luz me esclareceu!

Ainda na universidade, comecei a dar aulas de teatro. As escolas, de maneira geral, propiciam a seus alunos montagens de peças ao final de cada semestre ou ano. De 1989 até 2000, ano em que criei a Cia. Elevador de Teatro Panorâmico, pude experienciar e me experimentar como diretor, cenógrafo e iluminador nas montagens que realizava com os alunos. Nas escolas em que ensinava aprendia o ofício da direção - eu, que era ator da Cia. Razões Inversas, paralelamente me formava diretor de teatro.

Se Amilton Saraiva me ofereceu os primeiros recursos técnicos de iluminação, Marcio Aurélio me ofereceu os estéticos. Nos dez anos em que tra-

1. Entenda-se "bateria de luz" como um grupo de refletores dispostos em uma mesma região do espaço cênico, vetorizando um mesmo sentido. 
balhei na Razões Inversas aprimorei meu olhar por meio das escolhas que Marcio realizava, sempre vinculadas às estruturas significantes do espetáculo que estávamos criando. Do dégradé em azul de Torquato Tasso até a utilização de apenas dois colortrans em Maligno Baal, o associal. Do uso da lâmpada de sódio em A bilha quebrada até o longo lusco-fusco esfumaçado no prólogo de A arte da comédia.

Simultaneamente, nas escolas concebia os espetáculos visualizando a luz. Não desejei isso. Muito menos assim planejei. Aconteceu. Olhando para trás, percebo que, já naquela época, ao ver o ator no espaço, eu o via iluminado por alguma luz específica. $E$ isso com o passar do tempo só aumentou e se tornou, aos poucos, uma característica consciente.

Não me considero um iluminador profissional. Não trago em mim recursos técnicos, estudo sobre eletricidade, cursos de aprimoramento sobre as novas tecnologias, mesas computadorizadas. Aprendi em uma mesa analógica, e até hoje penso a luz analogicamente. Aprendi, ao longo do tempo, a iluminar a dramaturgia, a enfatizar tensões e revelar esvaziamentos. Aprendi que a luz me auxiliava na concepção de um mundo novo, um mundo próprio àquela história, àquela circunstância. A luz me ajudava a instaurar essas realidades ficcionais de acordo com minha sensibilidade. Na verdade, a luz tornava real o que antes era imaginação ficcional. E assim é. A luz materializa a realidade.

Como diz Godard em A chinesa (1967):

Personagem 1: A arte não reproduz o visível. Ela torna visível.

Personagem 2: Mas o efeito estético é imaginário.

Personagem 1: Sim, mas o imaginário não é o reflexo do real. É a realidade de seu reflexo.

Às vezes você ouve declarações como: use somente três cores, as três cores primárias: azul, amarelo e vermelho. Perfeitamente puras, perfeitamente equilibradas. Sob o pretexto de que todas as outras cores estão lá. Para tudo o que vemos, temos três coisas a considerar: a posição de quem vê, a posição do objeto, e a posição da fonte de luz (que incide sobre este objeto) $)^{2}$.

2. Tradução minha. 
Tornar visível o material sonhado por Eurípedes, Shakespeare, Goethe, Kleist, Büchner, Tchekhov, Brecht, Handke, Suassuna, Nelson Rodrigues, Cássio Pires, Samir Yazbek, Leonardo Cortez, autores que admiro e que são meus parceiros. Tornar visíveis os desejos e os anseios dos atores que muitas vezes me procuram com projetos pessoais, dedicados inteiramente a seu ofício. Tornar visíveis minhas inquietações, meus sonhos e pesadelos de artista de teatro. Saber que a criação cênica é um reflexo do que se imaginou, e que o reflexo é a própria realidade; momentânea, sim, fugaz, mas intensa, profunda, bela e transformadora.

"Para tudo o que vemos, temos três coisas a considerar: a posição de quem vê, a posição do objeto, e a posição da fonte de luz (que incide sobre este objeto)." Essa construção é aparentemente simples, mas, se lida com atenção, parece que todo o mundo cabe nela. Na frase há o ponto de vista e o campo de visão, o específico e o genérico, o personagem e a circunstância, a parte e o todo, o particular e o universal, a metonímia e a metáfora. Quando deparei com essa frase, muitas de minhas sensações a respeito do uso e da importância da luz na construção poética se esclareceram. O entendimento da posição das coisas, do objeto, do foco que o ilumina e de quem o vê revela aspectos ideológicos, morais, espirituais e estéticos. Revela-nos como sociedade. Talvez o mais importante é que a realidade depende, ao menos, do encontro dessas três posições. Elas são interdependentes. Não há hierarquias entre elas. Juntas se apresentam como fato. E, no meu modo de ver, nosso fazer artístico deve encontrar em si a força do fato.

Muito poderia me estender a respeito desse tema que me encanta e interessa, mas talvez não seja material para este artigo. Detenho-me agora a descrever três processos de criação em que o desenho de luz partiu e enfatizou aspectos diferentes, o que pode ilustrar, de certa forma, o uso que faço, como diretor/iluminador, dessa fonte criativa: Amor de improviso (2003), espetáculo processual improvisado em Campo de Visão; Eldorado, de Santiago Serrano (2008), que surgiu de uma pesquisa em mimese corpórea que o ator Eduardo Okamoto realizava com os rabequeiros no sul de São Paulo; e O jardim das cerejeiras, de Anton Tchekhov (2014), espetáculo que aflorou da necessidade da Cia. Elevador de olhar para a realidade cotidiana depois do trato com o material mítico em Ifigênia. 


\section{Quando a luz improvisa}

Amor de improviso é um espetáculo improvisado baseado no tema "amor", desenvolvido pela Cia. Elevador de Teatro Panorâmico, que teve sua primeira apresentação pública em 2003. É importante dizer que, ao longo desses anos, a peça esteve quatro anos ininterruptamente em cartaz, participou de diversos festivais pelo país e, nos últimos anos, encontra-se em repertório. Nela, a Elevador expõe seu sistema de criação, que vem sendo desenvolvido desde sua fundação: o Campo de Visão (LAZZARATTO, 2011).

Em poucas palavras, o Campo de Visão é um procedimento estético coral em que o ator toma o outro como elemento inspirador para sua própria criação, apropriando-se de movimentos alheios e se relacionando com todo e qualquer elemento que o estimule: música, espaço, objetos, palavras e imagens. O Campo de Visão promove, assim, uma experiência de alteridade, enfatizando um profundo diálogo entre indivíduo e coletividade. Estimula o ator a potencializar seu corpo como um corpo perceptivo, aberto às impregnações, na mesma medida em que o estimula a ser condutor/criador de suas escolhas estéticas. Com Amor de improviso, o Campo de Visão alcançou o estatuto de linguagem cênica, pois é criador e articulador de linguagem, tendo seus códigos e regras como estrutura.

Foi nesse trabalho que instituímos, em nosso fazer, a ideia de processo como obra. A apresentação do processo era a própria obra. Ou melhor, a obra era o processo. Como o espetáculo se define somente na improvisação, naquilo que não foi combinado, no que não foi marcado e estabelecido por ninguém, ao ser apresentado aparece não como algo definitivo, mas como esboço do que pode vir a ser. É nessa potencialidade, nessa possibilidade do vir a ser que ele atua. Aqui, o esboço não é algo que promete um dia se concretizar. Aqui, o esboço se configura como estética.

Amor de improviso pode ser entendido como tendo o conteúdo amor (tema) precipitado (ou precipitando) na forma Campo de Visão (linguagem). Atores, diretor/condutor (que também está em cena), iluminador, todos improvisam. A partir dos códigos do Campo de Visão, a cada dia acontece um novo espetáculo. O cenário é composto por uma lousa preta que divide o espaço vazio, uma caixa preta, em dois. A lousa como elemento didático recortando 
o jorro passional das criaturas enamoradas. O fluxo do rio e suas margens. A trilha sonora também é feita de improviso, no presente, operada e criada pelos próprios atores e pelo diretor/condutor.

E a iluminação?

Quando comecei a imaginar o que viria a ser Amor de improviso, me detive na ideia de que tudo seria tramado de maneira livre. Tudo entraria no jogo improvisacional, inclusive a iluminação. Para isso concebi uma estrutura de gerais e contras em dois tons de azul, diagonais, focos, focos a pino bem fechados, uma luz recortada na grande lousa, um corredor azul esverdeado iluminando atrás da lousa e luz de chão. Além do azul dos contras, uma diagonal vermelha.

Isso posto, cabia ao operador de luz entrar no jogo improvisacional nas apresentações e "pintar" a cena de acordo com sua sensibilidade e com o que estava acontecendo. Eu, que concebi o espetáculo, entregava ao operador a responsabilidade de iluminar e texturizar a peça livremente. Era dada a ele a possibilidade de enfatizar um acontecimento em detrimento de outro, de banhar a cena com determinado tom naquele momento, de privilegiar um movimento, enquanto o ator expressa seu texto no escuro e vice-versa. Porque em Amor de improviso tudo acontece simultaneamente, não há uma estória a ser contada, não há linearidade. Cada ator expressa seu estado enamorado livremente, na hora em que quiser e do jeito que quiser, mas profundamente atento aos outros e a tudo que o cerca, em profunda conexão e interação.

Da mesma forma age o operador de luz. Seu gesto de levantar um dimmer e não outro naquele momento é tão importante e definidor quanto um ator que resolve pronunciar suas palavras começando pelo fim, ou o diretor/condutor que resolve distribuir envelopes com algumas instruções do que deve ser feito naquele momento. Aos poucos a linguagem vai se estabelecendo naquele dia. Nesse espetáculo, a operação de luz tem força de ação.

Costumo usar a expressão "pintar a cena" porque acredito que seja isso que eu faça em meu trabalho. Há algo nessa expressão que aponta para uma poética, algo que nos leva ao inconsútil. Pintar com luz favorece a sensação de que o que vemos é um todo conectado. Uma realidade. Sem separações entre cenografia, atores e objetos, tudo integrado articulando um espaço e um tempo próprios. Pinto a cena com luz. Essa sinestesia tem muito a ver com a 
maneira como enxergo o fazer teatral. As fronteiras entre os elementos estéticos se esmaecem, e aquilo que pertence a um domínio ilumina o outro. A luz ilumina a tensão subjacente àquela circunstância como uma marca determina um ângulo de luz; a luz esclarece a emoção de certo personagem como as palavras do texto me esclarecem o filtro que devo usar.

Em Amor de improviso eu deixava essa rica e fundamental responsabilidade nas mãos do operador. Ele deveria desenvolver sua sensibilidade a partir dessas referências e fazer suas opções livremente. Meu trabalho como diretor/iluminador era, a cada apresentação, ouvir/sentir as escolhas feitas pelo operador, e por meio de longas conversas iluminar outras possibilidades de escolha que haviam passado despercebidas e valorizar aquelas que se mostraram relevantes. Ou seja, se tratava de um trabalho de iluminação indireta, voltado ao indivíduo criador ${ }^{3}$.

\section{Ouvir a luz}

Em 2008 fui convidado pelo ator Eduardo Okamoto para dirigi-lo em um espetáculo chamado Eldorado, com dramaturgia do argentino Santiago Serrano. Esse trabalho veio a público em 2009 e desde então está em repertório e se apresenta em várias localidades nacionais e internacionais. Por esse trabalho, Eduardo Okamoto foi indicado ao prêmio Shell de 2009. É um espetáculo que reúne percursos diversos. Autor, ator e diretor com trajetórias artísticas específicas ali se encontram imersos no homem-sertão; mergulhados no sertão, se ouso forçar a imagem. Imagem que tem como atributos a dor e a delícia da solidão. Do espaço vasto. Das amplidões. Das imaginações que muitas vezes são as únicas companheiras desse homem que lá vive e ousa enveredar sertão adentro.

Nesse trabalho nos interessou cuidar das palavras e de suas imagens, dos silêncios e de seus afetos, da jornada e de suas duas mãos: a mão de fora e a mão de dentro. Criar um lugar, teatral por excelência, em que deixamos de perceber a distinção entre essas instâncias. Porque tudo está nele,

3. Relato aqui um fato engraçado, porém significativo: certa vez, em um festival de teatro, ao saber dessa característica do espetáculo, o júri resolveu criar uma nova categoria de premiação, a operação de luz. Rodrigo Spina, o operador de Amor de improviso, ganhou o prêmio. 
nele ator, nele homem-sertão. Ele é ao mesmo tempo homem e geografia. Nele, tempo é espaço e espaço é tempo. Ele é o lugar de integração e descoberta, visando uma possível, e por que não, plenitude, para assim chegar a um Eldorado - momentâneo, sabemos, mas gostoso.

Ensaiamos esse espetáculo às tardes no espaço Elevador, sede da minha companhia teatral, a Cia. Elevador de Teatro Panorâmico. Faço aqui essa referência ao período em que ensaiávamos porque isso se mostrou fundamental para a concepção do espetáculo. A arquitetura do espaço àquela época guardava três janelas, uma ao lado do espaço cênico e duas ao fundo, todas em uma altura de mais ou menos 4,5 m. Devido a sua posição geográfica, naquele período do ano o sol invadia a janela lateral no início da tarde, e quando íamos chegando ao final do ensaio a luz solar invadia as janelas do fundo da cena.

Como diretor, pude observar essa característica ao longo dos ensaios, e certo dia pedi ao ator que, de olhos fechados, percebesse a incidência solar em seu corpo e no espaço e que tirasse proveito disso. Mas antes uma rápida sinopse da peça: Eldorado conta a trajetória de um rabequeiro cego que sai em andança em busca do Eldorado, região mítica de bonança e bem-estar, um paraíso na terra. Lugar de luz que iluminaria a escuridão de seus olhos! Quando Okamoto sentiu e entrou naqueles raios solares, interpretando o cego que sem guia se aventurava pelos mais diferentes lugares do território brasileiro - do planalto árido à floresta tropical -, estabelecendo diálogo com sua companheira, a rabeca (chamando-a de Menina em busca de sua terra prometida), eu observava a cena do lado de fora, antevendo o deslocamento solar que aconteceria até o final da tarde, quando num átimo toda a encenação se esclareceu: o cego seria contraditoriamente conduzido pela luz através de seus ouvidos de músico. Ele "ouviria a luz", e ela assim o guiaria.

A partir daí toda a marcação cênica, dinâmicas, ritmos e pulsões que eu propunha como diretor tinham esta frase como premissa: "o cego ouviria a luz". A cada nova chegada, a cada nova partida, uma nova luz "chamaria" o cego, e assim ele a seguiria em busca de Eldorado.

Como os aguilhões e apitos das peças curtas de Samuel Beckett, a luz seria uma espécie de força exterior que moveria, atiçaria, incomodaria, motivaria o homem a agir. A encontrar e a perder o caminho. A descobrir novas 
possibilidades e a se frustrar com a descoberta. A iluminação desse espetáculo surgiu então com essa tarefa conceitual: a luz seria o guia de um cego. A luz o moveria. O encheria de esperança, o esbofetearia, o levaria ao mar e à caatinga, à floresta e às suas lembranças...

Para isso, a caixa preta era essencial. Ela representaria o espaço interior dos olhos do cego: escuro, sem luz. Um nada. Uma ontologia. Os fachos de luz seriam a voz, o som que o estimulariam. Assim, dispus no espaço os refletores. Suas características, ângulos, posicionamentos e filtros indicavam por onde o cego deveria ir e onde ele se encontrava. Cada local ou cada percurso era iluminado por uma qualidade de luz. Poderia mesmo dizer que tal deslocamento se dava sob Elipsoidais, outro por Fresnéis, outro ainda por PCs etc. As posições dos refletores também demarcariam territórios e iluminariam estradas e locais: diagonais - frentes e contras, altas e baixas; luz lateral bai$\mathrm{xa}$ - direita e esquerda; focos - a pino e frontais; tons de cores evidenciando algumas regiões geográficas e um fino ajuste de intensidades nos ajudavam a construir a dramaturgia da cena. O cego "ouvia" a luz, e a cada nova luz sua expectativa por Eldorado aumentava. Sua esperança crescia. E assim, sem nada, somente com a Menina nos braços, ele adquiria forças para continuar sua jornada.

A arquitetura do local de ensaio e sua relação com a luz solar propiciaram estabelecer uma profunda relação com a dramaturgia e as características do personagem. Isso, somado às qualidades expressivas do ator, me deram todos os ingredientes, conceituais e instrumentais para a concepção do espetáculo e sua iluminação.

\section{Um jardim impressionista}

Recentemente eu trouxe a público, com a Cia. Elevador de Teatro Panorâmico, uma encenação de $\mathrm{O}$ jardim das cerejeiras, último texto de Tchekhov, em que enfatizo o aspecto impressionista de sua obra.

A obra de Tchekhov se esmera em revelar ao espectador espaços daquilo que não é dito, e para isso conduz as ações através de um tempo-ritmo peculiar: um tempo largo que gesta um estado de suspensão. Em nosso Jardim das cerejeiras, essa suspensão ajudava a compor a sensação de qua- 
dros vivos, verdadeiras paisagens, em que se perdia a distinção entre pausa e movimento. Inspirados por Tchekhov, suavizamos as fronteiras entre tempo e espaço, pausa e movimento, interioridade e exterioridade, oferecendo ao espectador, de acordo com sua sensibilidade, a percepção das fronteiras: um gesto impressionista.

Cenografia, figurino e iluminação foram concebidos visando a um esfumaçamento dos contornos. A interpretação dos atores nascia antes da latência do que de um gesto característico, apoiada em uma atuação estática que privilegiava os estados ao movimento. Por outro lado, a marcação cênica desenhava linhas claras e objetivas visando à elaboração de camadas e profundidades espaciais, gerando verdadeiras telas emolduradas pela caixa cênica do teatro.

O jardim das cerejeiras é uma peça e também uma paisagem. Na obra de Tchekhov, o jardim das cerejeiras é muito mais do que um simples jardim; é um símbolo que representa todo um povo, toda a nação: "nosso jardim é a Rússia inteira", fala Trofímov a certa altura da peça. Um símbolo de uma época, da derrocada da aristocracia, da manutenção da escravidão, da preservação da beleza... Mas também não deixa de ser um simples jardim. Uma paisagem larga e profunda que causa tamanha identificação, que todos os personagens, de certo modo, ao passarem por ele, passam por si; ao vê-lo, nele se enxergam, e tudo isso como uma sensação de simultaneidade.

Nos desvãos dos pensamentos dos personagens, nas brechas do tempo entre uma ação e outra, percebemos que os desejos individuais dos personagens, seus objetivos diretos ou sua inércia, estão inseridos em algo maior que eles mesmos. Toda ação individual acontece em um lugar que a cerca. Estamos sempre inseridos em uma paisagem, e essa relação é tão profunda que, ao estarmos inseridos, a somos; e os traços de identidade de cada personagem fazem dessa paisagem, através deles, algo um pouco diferente. A profunda relação que os personagens têm com o jardim, seja porque o amam, seja porque o detestam, seja porque veem nele uma possibilidade real de prosperidade, seja porque sentem e sabem que ali é o seu lugar, o seu lar, a sua vida, fez que concebêssemos $O$ jardim das cerejeiras como uma paisagem de pinceladas impressionistas.

E aqui, para conquistarmos tal objetivo, a iluminação foi essencial... 
Quando eu era mais jovem, tendia a usar filtros com cores intensas. $\mathrm{Na}$ paleta de cores, sempre me inclinava para as mais fortes. Tudo era intenso. Minha inquietude, minha visão, minha sensibilidade, eram constituídas de tons vibrantes. Com o passar do tempo, aos poucos, comecei a escolher apenas um tom quente e um frio para pintar a cena. Logo depois disso e durante certo tempo, todas as peças que iluminava tinham a mesma escolha de filtros. O que mudava era a escolha de refletores, os ângulos e principalmente o uso das intensidades. O azul e o amarelo começaram a mandar em meus espetáculos. Todos tinham o azul e o amarelo. Mas o resultado final era completamente diferente. Tudo dependia da posição do objeto, da posição do foco de luz e de quem a via... O uso dos mesmos filtros geravam espetáculos com luzes completamente diferentes.

Passado mais um tempo, agora em $\mathrm{O}$ jardim das cerejeiras, esmaeci por completo os tons, embora a relação entre o quente e o frio fosse ainda determinante. Ainda mais para a gelada Rússia! Aqui tudo vai de um amarelo esmaecido a um lilás esmaecido. Esmaecimento. A luz contribui ao gesto impressionista do espetáculo através do esmaecimento dos tons que iluminam a cena em contraste com os tons fortes que iluminam uma espécie de ciclorama atrás das teias de fios que constituem o cenário. Esse contraste entre esmaecimento e intensidade foi o que iluminou o caminho para que o espetáculo passasse pelas quatro estações do ano indiciadas na obra por Tchekhov. A primavera no primeiro ato e a volta de Liuba Andrêievna à sua casa; o verão no segundo ato e os personagens ao ar livre em pura contemplação e divagação filosófica; o outono no terceiro ato e a festa em casa de Liuba no dia em que acontece o leilão de sua propriedade; e o inverno no quarto ato, quando Liuba e sua família deixam a propriedade que fora vendida e o jardim será derrubado para a construção de pequenas vilas de veraneio.

Sobre o cenário branco e seus quilômetros de fios pendurados incidiam raios solares e lunares; tons de interiores e intensidade exterior, tudo sem definições de foco... Esmaecimento. Como o daquelas vidas esmaecidas, daquele tempo... que esmaeceu.

Acredito que seja assim que pense a luz em meus trabalhos. Ela está a serviço de algo maior do que si mesma. Como tudo no teatro. Cada parte, cada instrumento, cada operação artística sinestesicamente se integra às ou- 
tras para que, juntas, e sem percebermos ao certo as distinções entre elas, contribuam para o todo do espetáculo. Este, sim, maior do que as vontades do autor, maior do que a vontade dos atores, maior do que a vontade do diretor. A obra é maior do que tudo e todos juntos. E estamos sempre a seu serviço.

\section{Referências bibliográficas}

AMOR de Improviso. Direção: Marcelo Lazzaratto. Cia. Elevador de Teatro Panorâmico, 2003. Disponível em: <https://www.youtube.com/watch?v=gm0UfldVLH0>. Acesso em: 4 set. 2015.

CAMARGO, R. G. A função estética da luz. São Paulo: Perspectiva, 2012.

ELDORADO. Direção: Marcelo Lazzaratto. Cia. Elevador de Teatro Panorâmico, 2009. Disponível em: <https://www.youtube.com/watch?v=ol06H0llwi0>. Acesso em: 4 set. 2015.

LA CHINOISE (A CHINESA). Direção: Jean-Luc Godard. Anouchka Films, 1967. (96 min.), son., color.

LAZZARATTO, M. R. Campo de Visão: exercício e linguagem cênica. São Paulo: Escola Superior de Artes Célia Helena, 2011.

O JARDIM das Cerejeiras. Direção: Marcelo Lazzaratto. Cia. Elevador de Teatro Panorâmico, 2014. Disponível em: <http://youtu.be/J1R445sGrGU>. Acesso em: 4 set. 2015.

SARRAZAC, J.-P. Léxico do drama moderno e contemporâneo. São Paulo: Cosac Naify, 2012.

SHAPIRO, M. Impressionismo. São Paulo: Cosac Naify, 2002.

TCHEKHOV, A. O jardim das cerejeiras/Tio Vânia. Porto Alegre: L\&PM, 2009.

Recebido em 30/07/2015

Aprovado em 30/08/2015

Publicado em 21/12/2015 